\title{
A prática das enfermeiras obstétricas nas emergências vinculadas ao Programa Cegonha Carioca
}

\author{
Obstetric nurses' practice on emergency wards under the Cegonha Carioca Program \\ La práctica de las enfermeras obstétricas en las emergencias vinculadas al Programa \\ Cigüeña Carioca
}

\author{
Jane Marcia Progianti', Adriana Lenho de Figueiredo Pereira ${ }^{\text {II }}$ Carla Coutinho Sento SéIII
}

\begin{abstract}
RESUMO: Trata-se de um estudo qualitativo que visou discutir a prática das enfermeiras obstétricas nas emergências das maternidades vinculadas ao Programa Cegonha Carioca. O estudo apoia-se conceitualmente nas noções de práxis reiterativa e criadora. A coleta de dados foi realizada de janeiro a março de 2013, em quatro maternidades públicas do município do Rio de Janeiro, com oito enfermeiras obstétricas que concederam uma entrevista semiestruturada. A análise dos depoimentos seguiu os seguintes passos: ordenação, classificação, categorização dos dados e análise final. Os resultados apontaram o acolhimento como prática ambivalente, a visita programada à maternidade com a finalidade de preparo e ambientação para o parto e classificação de risco e pós-consulta como práticas de apoio e reforço ao atendimento médico. Conclui-se que a prática da enfermeira obstétrica no módulo acolhimento é uma práxis reiterativa e que, apesar de ser pautada na humanização, sofre forte influência do modelo biomédico hegemônico.
\end{abstract}

Palavras-Chave: Política de saúde; saúde da mulher; acolhimento; enfermagem obstétrica.

\begin{abstract}
The goal of this qualitative study was to discuss obstetric nurses' practice on emergency ward at maternity hospitals linked to the Cegonha Carioca Program. The study is based conceptually on the notions of reiterative and creative praxis. Data were collected between January and March 2013, by semistructured interview of eight obstetric nurses at four public maternity hospitals. The analysis of their statements involved the following steps: sorting, classification, data categorization, and final analysis. The results showed that the practice of user embracement was ambivalent and that the visits scheduled to maternity wards for the purpose of preparation and familiarization with childbirth and risk classification and aftercare guidance, were practices that supported and reinforced medical care. It was concluded that obstetric nurses' practice during user embracement is a reiterative praxis and that, although based on humanization, is strongly influenced by the hegemonic biomedical model. Keywords: health policy; women's health; user embracement; obstetric nursing.

RESUMEN: Este es un estudio cualitativo que tuvo como finalidad discutir la práctica de las enfermeras obstétricas en las emergencias de las maternidades vinculadas al Programa Cigüeña Carioca. El estudio se basa conceptualmente en las nociones de praxis reiterativa y creadora. Los datos fueron recogidos entre enero y marzo de 2013, en cuatro maternidades públicas de Rio de Janeiro - Brasil, con ocho enfermeras obstétricas que participaron en entrevistas semiestructuradas. El análisis de los testimonios siguió los siguientes pasos: ordenación; clasificación; categorización de los datos; y análisis final. Los resultados mostraron el acogimiento como una práctica ambivalente; las visitas programadas a la maternidad, con la finalidad de preparo y ambientación para el parto; clasificación de riesgo y post-consulta como prácticas de apoyo y refuerzo a la atención médica. Se concluye que la práctica de la enfermera obstétrica en el acogimiento es una praxis reiterativa y que, a pesar de estar basada en la humanización, sufre fuerte influencia del modelo biomédico hegemónico.

Palabras Clave: Política de salud; salud de la mujer; acogimiento; enfermería obstétrica.
\end{abstract}

\section{INTRODUÇÃO}

No ano de 2010, o Ministério da Saúde publicou as Diretrizes para Organização da Rede de Atenção à Saúde, no âmbito Sistema Único de Saúde (SUS), através da Portaria no-4279 de 30 de dezembro de 2010. Nesta legislação, existe a definição de Rede de Atenção à Saúde (RAS) como sendo arranjos organizativos de ações e serviços de saúde, de diferentes densidades tecnológicas, que integradas por meio de sistemas de apoio técnico, logístico e de gestão, buscam garantir a integralidade do cuidado ${ }^{1}$.

A RAS caracteriza-se pela formação de relações horizontais entre os pontos de atenção primária, se-

${ }^{I}$ Enfermeira Obstétrica. Doutora em Enfermagem. Docente da Faculdade de Enfermagem, Professora Associada, Pesquisadora do Grupo de Pesquisas sobre Gênero, Poder e Violência na Saúde e Enfermagem e do Programa de Prociência da Universidade do Estado do Rio de Janeiro. Brasil. E-mail: jmprogi@uol.com. IIProfessora Adjunta do Departamento de Enfermagem Materno-Infantil. Faculdade de Enfermagem. Universidade do Estado do Rio de Janeiro. Brasil. E-mail: adrianalenho.uerj@gmail.com.

IIIEnfermeira e Mestre pelo Programa de Pós-Graduação em Enfermagem da Universidade do Estado do Rio de Janeiro. Brasil. E-mail: carlacsentose@gmail.com 
cundária e terciária. Estes pontos de atenção à saúde são entendidos como espaços onde se ofertam determinados serviços de saúde, por meio de uma produção singular, e são igualmente importantes para que se cumpram os objetivos da rede. Eles se diferenciam, apenas, pelas distintas densidades tecnológicas que os caracterizam ${ }^{1}$.

Nessa perspectiva de melhoria da organização, funcionamento e resolubilidade da rede assistencial na área materno-infantil, foram lançados simultaneamente, a Rede Cegonha, em âmbito Federal, e o Programa Cegonha Carioca, no município do Rio de Janeiro, em 28 de março de 2011.

O referido programa, por sua vez, busca ampliar e qualificar a assistência prestada às gestantes no município do Rio de Janeiro. É composto de três módulos: prénatal, transporte e acolhimento. $\mathrm{O}$ módulo pré-natal intenta possibilitar às gestantes, inscritas no pré-natal da atenção básica, o conhecimento prévio da maternidade de referência para a assistência ao parto. $\bigcirc$ módulo transporte é caracterizado pela disponibilização de serviço de atendimento móvel às parturientes que necessitam de remoção do domicílio para a maternidade ${ }^{2}$.

Por fim, o módulo acolhimento intenta reorganizar e qualificar as emergências obstétricas nas maternidades municipais. A garantia da continuidade da assistência entre os momentos do pré-natal e do parto é considerada uma importante estratégia para a redução da morbimortalidade materna e neonatal ${ }^{2}$.

Com a implementação do módulo acolhimento, instituiu-se um novo cenário da prática profissional das enfermeiras obstétricas nas emergências das maternidades municipais. Diante desse novo cenário, este estudo objetivou discutir a prática das enfermeiras obstétricas nas emergências das maternidades vinculadas ao Programa Cegonha Carioca.

\section{REVISÃO DE LITERATURA}

A prática das enfermeiras obstétricas no módulo acolhimento não pode ser analisada de modo pragmático, como uma mera objetivação de ações programáticas recomendadas, mas enquanto uma atividade conscientemente orientada, uma totalidade teórico-prática indissociável, que tem um lado ideal, teórico, e um lado material, propriamente prático, que não podem ser isolados um do outro, o que nos remete ao conceito de práxis ${ }^{3}$.

A práxis é ação do homem sobre a matéria e criação de uma nova realidade, pode-se falar de diferentes níveis, de acordo com o grau de penetração da consciência do sujeito ativo no processo prático e com o grau de criação ou humanização da matéria transformada evidenciado no produto de sua atividade prática. Há distinção de dois níveis de práxis, a criadora (reflexiva) e a reiterativa (espontânea ou imitativa), que formam dois polos de tensão dialética constitutiva da práxis humana ${ }^{3}$.
A práxis criadora é determinante para produzir uma nova realidade, a práxis reiterativa não produz uma mudança qualitativa da realidade presente e não a transforma criadoramente, ainda que possibilite a área do que já foi criado, multiplicar quantitativamente o que já foi outrora criado ${ }^{3}$.

\section{Metodologia}

Trata-se de uma pesquisa qualitativa, cuja coleta de dados foi realizada em quatro maternidades públicas de grande porte do município do Rio de Janeiro, que possuem equipes do módulo acolhimento, atuando nas suas emergências. $\mathrm{O}$ período de coleta de dados foi de janeiro a março de 2013.

As participantes da pesquisa foram oito enfermeiras obstétricas, que atuavam por pelo menos seis meses no módulo acolhimento, nas maternidades municipais estudadas, e que aceitaram participar do estudo.

A pesquisa foi aprovada pelo Comitê de Ética em Pesquisa da SMS-RJ, sob o no 92/11 atendendo à Resolução nº 466/2012 do Conselho Nacional de Saúde, que direciona as pesquisas envolvendo seres humanos. As depoentes assinaram o termo de Consentimento Livre e Esclarecido.

A coleta dos dados foi realizada através de uma entrevista semiestruturada. O roteiro de entrevista aplicado às enfermeiras obstétricas constou de seis perguntas para caracterização da depoente e cinco para responder ao objetivo desta pesquisa. Ressalta-se que para preservar o anonimato, as depoentes foram identificadas por meio de letras e números, conforme a ordem de realização de entrevistas: Enfermeira (E1), Enfermeira (E2)...

A análise dos depoimentos seguiu os seguintes passos: ordenação dos dados, através da transcrição das entrevistas, releitura do material transcrito, classificação dos dados, com leitura horizontal e exaustiva dos textos e leitura transversal de cada subconjunto apresentado e análise final ${ }^{4}$.

\section{Resultados e Discussão}

Seguindo esse percurso analítico, foram construídas três categorias: Acolhimento como prática ambivalente; Visita programada à maternidade: preparo e ambientação para o parto; e Classificação de risco e pós-consulta: práticas de apoio e reforço ao atendimento médico.

\section{Acolhimento como prática ambivalente}

$\mathrm{O}$ acolhimento, apesar de suas diversidades de concepções e configurações, é um processo em construção no SUS onde as ações de saúde expressam a racionalidade implícita nos modelos assistenciais, que é uma forma de pensar, conceber e ser no mundo em uma dada época, que determina as ações, estabelece padrões e produz sentidos, significados e práticas sociais ${ }^{5}$. 
Nesse sentido foi revelado que algumas enfermeiras concebem o acolhimento como sendo a escuta sobre os problemas da mulher, recepção e segurança e o realiza durante todo o processo de atendimento:

Acolhimento é a escuta, é você recepcionar, ouvir, dar segurança. É a mulher se sentir acolhida, se sentir bem para expor seus problemas, que nem sempre são obstétricos. (E1)

O acolhimento acontece o tempo todo, desde a entrada dela [usuária] até o momento da saída, acolhendo no momento de verificação dos sinais vitais, depois do atendimento médico, no momento que ela passa pela medicação. (E2)

Tais depoimentos denotam também que o olhar da enfermeira centra nos problemas da mulher de maneira ampliada e em seus sentimentos de bem-estar. Nessa perspectiva, o acolhimento passa nortear sua prática porque está presente de modo contínuo na postura da profissional, podendo ser considerado uma ação técnicoassistencial com foco nas relações, que pressupõe um modo de operar os processos de trabalho em saúde, como a escuta, a construção de vínculo, a garantia do acesso com responsabilização e a resolubilidade da assistência prestada, e por isso mesmo, pode ser considerado uma das diretrizes de maior relevância ética e estética da Política Nacional de Humanização do SUS ${ }^{6,7}$.

No entanto, o modo de produção hegemônico em saúde é norteado pelo modelo biomédico, que tem ênfase na medicalização e na concepção de risco, fazendo com que haja tendência de transformar todas as queixas em transtorno ou doença biológica passível de tratamento e dependente das tecnologias biomédicas ${ }^{8}$.

Essa visão de mundo hegemonicamente presente nos espaços de atendimento influencia a prática das enfermeiras, tanto que o acolhimento também foi concebido como uma escuta das queixas atuais das mulheres para a resolução de problemas emergenciais.

$\mathrm{O}$ acolhimento é a escuta. Eu escuto a queixa e tenho que estar atenta se não é um sangramento. Se não tem médico, aqui embaixo, eu coloco no repouso, instalo soro e oxigênio, já colho o exame de sangue e encaminho para o laboratório. (E5)

O último depoimento evidencia a reprodução pela enfermeira do modelo clínico, centrado na queixa da doença. Isso define as ações profissionais, restringindo o espaço para ações educativas, de promoção e prevenção à saúde 5 .

Essa concepção deixa claro uma faceta da enfermagem obstétrica que dá ênfase aos saberes biológicos, nas regras e normas instrumentais da profissão e na posição nuclear do médico no atendimento em saúde. Nessa perspectiva, o acolhimento foi reduzido a mais um procedimento, cuja concepção não foi incorporada à postura profissional da enfermeira, a ponto de estar presente em todo o processo de atendimento, demon- strando um modo de produção de cuidado fragmentado em uma série de operações parciais. Essa divisão se converte em uma divisão do próprio homem, que põe todo o seu ser a serviço de uma única atividade ${ }^{3}$.

A maneira como é operacionalizado, o módulo acolhimento denota que a atribuição de acolher, de efetivar a dimensão subjetiva e relacional do cuidado à mulher, está sob responsabilidade da enfermeira e circunscrita ao pequeno espaço de uma sala no setor de emergência da maternidade.

As condições de trabalho, naquela sala, são muito difíceis, porque o espaço épequeno, restrito. Eu acho que a gestante deveria ter um pouco mais de privacidade. A gente tem apenas um biombo. Daí, quando eu tenho que examinar, percebo que a gestante fica nitidamente incomodada. (E8)

Até hoje acho que nossa sala não é um ambiente acolhedor, não é um local que a gente consiga receber a gestante com privacidade, de conversar, de receber o acompanhante dela. (E7)

Portanto, há uma nítida segmentação técnica e espacial, entre o lugar previsto para a prática do acolhimento e para a prática do atendimento clínicoobstétrico, o que não viabiliza os ideais programáticos do acolhimento como um modo de operar os processos de trabalho em saúde?.

\section{Visita programada à maternidade: preparo e ambientação para o cenário do parto}

Toda ação humana requer certa consciência de uma finalidade, que se sujeita ao curso da própria atividade, ou seja, a finalidade é a expressão de certa atitude do sujeito em face da realidade ${ }^{3}$.

Nessa perspectiva, o módulo acolhimento, na área obstétrica, introduziu ações diferenciadas ao que é comumente realizado nos serviços de urgência. Foi instituída a visita programada das gestantes, no terceiro trimestre de gravidez, e de seu acompanhante às maternidades de referência. Esta é uma estratégia de continuidade da linha do cuidado entre os serviços da atenção básica, que realizam o acompanhamento prénatal, com as maternidades, pertencentes à atenção secundária, como garantia da referência para o parto prevista na Lei Federal n ${ }^{\circ} 1634$ de 27 de dezembro de 2007. Esta Lei assegura o direito ao conhecimento e à vinculação prévia à maternidade na qual ocorrerá seu parto e o atendimento nos casos de intercorrências.

Durante essa visita, são apresentadas as dependências físicas da maternidade, discutidas questões relacionadas ao trabalho de parto e o momento de buscar a maternidade, como descreve a enfermeira:

Nós temos ainda a atribuição dessas oficinas educativas para a mulher conhecer a unidade a que ela é referenciada e saber em que momento vai buscar a emergência para, justamente, não ficar peregrinando. Então, nós procuramos colocar nas oficinas educativas as principais 
situações de queixa que elas têm, focamos não só na questão dos sinais do trabalho de parto, do parto como processo final, mas também nas principais situações de emergência para elas buscarem atendimento. (E4)

Percebe-se que as atividades da visita são consideradas como práticas de menor complexidade técnica, que não requerem a atuação de uma profissional especializada em obstetrícia.

Por outro lado, as orientações oferecidas para gestantes no momento desta visita não podem ser entendidas propriamente como uma oficina educativa. $\bigcirc$ processo educativo em saúde, sob perspectiva do compartilhamento de saberes e da autonomia do sujeito no processo de construção do conhecimento, não é uma tarefa simples e que se dá num breve encontro na instituição. Educar em saúde significa efetivar o processo de reflexão da realidade por meio do diálogo e da troca de experiências entre os sujeitos, que elevam sua consciência sobre si e sobre sua realidade ${ }^{10}$.

Além dessa perspectiva acanhada de atividade educativa, no momento da visita também ocorre a distribuição de uma bolsa decorada com o logotipo do Programa, que tem roupas para o bebê, denominada de Enxoval Cegonha. A distribuição desse enxoval visa incentivar a adesão das mulheres ao pré-natal e aumentar a cobertura da assistência no município do Rio de Janeiro ${ }^{11}$.

No entanto, sua distribuição denota também a lógica assistencialista subjacente na implementação do Programa, que decorre da tradição das políticas sociais direcionadas aos pobres no país. Esses compõem a classe social predominante dos usuários nos serviços públicos de saúde.

Assim sendo, a prática da enfermeira na visita programada à maternidade assume sentidos de ordem técnica, operacional e política. $\mathrm{O}$ primeiro sentido representa as atividades que elas realizam no módulo acolhimento, que são estratégicas para a garantia de direitos das gestantes em relação à referência para o parto e ao conhecimento do ambiente em que seu filho irá nascer. A visita também é uma oportunidade de aquisição de informações pelas gestantes sobre quando e em quais situações devem recorrer ao atendimento de emergência da maternidade, o que contribui com a reorganização dessa porta de entrada da atenção secundária.

Por fim, viabiliza a divulgação de uma ação programática da gestão governamental por meio da oferta de brinde para as gestantes inscritas no Programa Cegonha Carioca, cuja utilidade transcende o objetivo de melhoria da atenção obstétrica.

\section{Classificação de risco e pós-consulta: práticas de apoio e reforço do atendimento médico}

O Programa Cegonha Carioca estabelece que a usuária, ao chegar ao serviço de emergência, deve ser recebida pelos profissionais administrativos responsáveis pela expedição do Boletim de Atendimento de
Emergência e, posteriormente, ser encaminhada para a sala onde ocorrerá a classificação de risco. Esta é vista como uma ferramenta técnico-assistencial que organiza o atendimento com base no risco e na vulnerabilidade da usuária e não pela ordem de chegada, o que é potencialmente prejudicial para a saúde da gestante e de seu concepto nas situações de urgência e emergência ${ }^{11}$.

Nessa sala, a enfermeira obstétrica acolhe a gestante, verifica os sinais vitais, identifica o risco e estabelece o grau de prioridade para o atendimento médico, de acordo com um protocolo padronizado, como descreve a enfermeira:

Eu recebo a gestante, ouço o que ela tem a me dizer, afiro os sinais vitais e classifico de acordo com urgência, emergência delas, priorizando ou não o atendimento médico. Tem um protocolo que a gente vai observando de acordo com o que ela está sentindo, com o que a gente está vendo, para poder priorizar o atendimento, o tempo que ela pode esperar para não agravar a situação dela. (E6)

Apesar de estabelecer a prioridade para o atendimento do médico, nem sempre este profissional está presente na equipe das emergências obstétricas, o que exige das enfermeiras obstétricas a responsabilização pela assistência de emergência, como descrito nos depoimentos a seguir:

As minhas atividades são o acolhimento, escutar a gestante, priorizar o atendimento médico. Nem sempre tem médico obstetra no atendimento, ou então, tem e estão ocupados, e a gente precisa atuar na avaliação dela, no toque ou até mesmo na assistência ao parto ou ao RN que já nasceu. (E1)

Conforme você escuta a história e as queixas da mulher, você vai classificar pelo tempo necessário do atendimento dela. Só que na nossa unidade a gente tem problema em relação ao quantitativo da equipe médica. Mas a principal função é a de detectar o risco, o grau de risco dessa mulher, da necessidade que ela está apresentando nesse momento e procurar minimizar a situação dela. (E4)

A redução do quantitativo de médicos nos serviços públicos de saúde é uma das consequências do subfinanciamento crônico, das dificuldades estruturais do sistema de saúde, da baixa remuneração e das adversas condições do trabalho em saúde. Esta precarização do trabalho tende a afastar os médicos do serviço público de saúde, já que estes encontram condições de trabalho mais favoráveis no serviço privado.

A carência desses profissionais no setor público de saúde tem sido veiculada pelos meios de comunicação. $\mathrm{O}$ déficit desses profissionais prejudica o atendimento nas emergências e provoca o fechamento de leitos hospitalares. O município do Rio de Janeiro realiza concursos públicos para o seu quadro permanente de médicos, porém as baixas remunerações não favorecem a retenção desses profissionais ${ }^{12}$. 
Assim como os médicos, a enfermagem também enfrenta essa problemática nas condições de trabalho. Apesar das diferenças no processo de profissionalização da enfermagem e da medicina, as questões de gênero e de classe social estão no cerne da divisão social e sexual do trabalho em saúde, e produzem distinções socioprofissionais que repercutem na diferenciação do valor social e financeiro do trabalho do médico e da enfermeira.

Além disso, a organização do trabalho no hospital tem um ordenamento burocrático e hierárquico, determinado também por essas questões e que conformam a divisão de tarefas e de atribuições na instituição. Por meio desse ordenamento, há o controle do tempo, dos processos e dos modos de execução das atividades e, consequentemente, cria os comandos, as responsabilidades, as hierarquias, as relações de poder e as cadeias de interações e interdependências dos sujeitos no processo laboral ${ }^{13}$.

No âmbito desse ordenamento, as ações realizadas pelas enfermeiras obstétricas no módulo acolhimento das emergências apoiam e agilizam o atendimento médico, mas também o reforçam por meio da prática do pós-acolhimento. Este ocorre após o atendimento médico, quando a mulher retorna para enfermeira para sanar possíveis dúvidas acerca do que foi dito pelo médico e intermediar a resolução de algumas situações que ainda demandam cuidados:

Eu preencho esse papel [ficha de classificação de risco], digo a queixa dela, se ela está com alguma queixa, encaminho para o atendimento médico. Depois desse atendimento ela volta para mim, para saber se ela foi bem orientada, se tem alguma dúvida. (E3)

Considerando as recomendações ministeriais para a organização do acolhimento com classificação de risco nos serviços de urgência do SUS, a atividade adicional do pós-acolhimento assume uma conformação talvez inédita, em que o acolhimento realizado pela enfermeira obstétrica é o momento inicial do atendimento no setor de emergência das maternidades, mas também o momento de sua resolução, quer seja para indicação de continuidade da assistência no pré-natal da atenção básica ou para o seguimento nos demais setores da maternidade.

Na perspectiva da práxis criadora, tal fato poderia ser determinante para produzir uma nova realidade ou uma mudança qualitativa da realidade presente, levando inclusive à criação de uma demanda social (de usuárias do SUS) que reivindicasse seus direitos de participação na construção de seus próprios cuidados, mediante seus saberes e necessidades ${ }^{14}$.

\section{ConClusão}

Por ser a práxis da enfermeira obstétrica no módulo acolhimento fragmentada, pautada em ações protocolares e com centralidade nas ações do médico, conclui-se que ela é uma práxis reiterativa.
Essa práxis reiterativa inviabiliza a criação de alternativas para a transformação concreta do modo de produção do cuidado obstétrico e a superação do modelo biomédico hegemônico e das relações de produção decorrentes.

Assim, apesar de as enfermeiras obstétricas terem uma formação e atuação que as identificam com o ideário da humanização, no que tange a proporcionar à mulher e ao seu acompanhante um atendimento centrado na integralidade das necessidades apresentadas, estas profissionais têm sua prática estruturada pela lógica de mercado e produtividade, o que sinaliza o direcionamento da reorganização produtiva do trabalho em saúde do município do Rio de Janeiro.

O acolhimento é ambivalente, ora é entendido como uma recepção, ora perpassa todo atendimento. Essa prática é influenciada pela falta de infraestrutura física de algumas unidades e pela lógica protocolar instituída.

Essa instituição de protocolos e o preenchimento das fichas de classificação de risco colaboram para que a enfermeira dê maior ênfase aos procedimentos protocolares, que são os dados objetivos e mensuráveis da produção das atividades programáticas em detrimento das subjetividades do cuidado de enfermagem.

Sugere-se aos gestores e às enfermeiras do módulo acolhimento que elaborem estratégias de gestão que possam equilibrar as ações de cumprimento dos protocolos com as ações subjetivas do cuidado de enfermagem, como por exemplo, instituir a avaliação qualitativa do serviço, criar grupos de práticas educativas que sejam emancipadoras para o exercício da cidadania.

\section{REFERÊNCIAS}

1.Ministério da Saúde (Br). Portaria no 4279, de 30 de dezembro de 2010: Diretrizes para Organização da Rede de Atenção à Saúde do SUS. Brasília (DF): Diário Oficial da União; 31 dez. 2010, Seção 1, p. 88-93.

2.Secretaria Municipal de Saúde e Defesa Civil do Rio de Janeiro. Convocação pública para parcerias com organizações sociais: Programa Cegonha Carioca. Módulo Acolhimento. [citado em 10 out 2014]. Rio de Janeiro, 2010. Disponível em: http://www.rio.rj.gov.br/web/smsdc/ exibeconteudo? articleid $=1194953$.

3.Vazquez AS. Filosofia da práxis. 2a ed. Buenos Aires (Ar): Consejo Latinoamericano de Ciencias Sociales Clacso; 2011.

4.Minayo MCS. O desafio do conhecimento: pesquisa qualitativa em saúde. São Paulo: HUCITEC; 2011.

5.Mitre SM, Andrade EIG, Cotta RMM. Avanços e desafios do acolhimento na operacionalização e qualificação do Sistema Único de Saúde na Atenção Primária: um resgate da produção bibliográfica do Brasil. Ciênc. saúde coletiva. 2012; 17: 2071-85.

6.Ministério da Saúde (Br). Secretaria de Atenção à Saúde. Política Nacional de Humanização da Atenção e Gestão do SUS. Acolhimento e classificação de risco nos 
serviços de urgência. Brasília (DF): Editora MS; 2009. 7.Ministério da Saúde (Br). Secretaria de Atenção a Saúde. Núcleo Técnico da Política Nacional de Humanização. Acolhimento nas práticas de produção de saúde. Brasília (DF): Editora MS; 2006.

8.Tesser CD, Poli NP, Campos GWS. Acolhimento e (des) medicalização social: um desafio para as equipes de saúde da família. Ciênc saúde coletiva. 2010; 15: 3615-24.

9. Dal Pai D, Lautert L. Sofrimento no trabalho de enfermagem: reflexos do 'discurso vazio' no acolhimento com classificação de risco. Esc Anna Nery. 2011; 15: 524-30. 10.Rigon AG, Neves ET. Educação em saúde e a atuação de enfermagem no contexto de unidades de internação hospitalar: o que tem sido ou há para ser dito? Texto contexto - enferm. 2011; 20: 812-7.

11.Secretaria Municipal de Saúde e Defesa Civil do Rio de Janeiro. Convocação pública para parcerias com or- ganizações sociais: Programa Cegonha Carioca. Módulo Acolhimento. Rio de Janeiro, 2010. [citado em 10 out 2014]. Disponível em: http://www.rio.rj.gov.br/web/ smsdc/exibeconteudo? articleid $=1194953$.

12.Abdala V. Agência Brasil [site de Internet]. CREMERJ diz que falta de médicos compromete saúde pública no Rio de Janeiro. [citado em 10 out 2014]. Disponível em: http://agenciabrasil.ebc.com.br/noticia/2013-06-29/ cremerj-diz-que-falta-de-medicos-compromete-saudepublica-no-rio-de-janeiro.

13.Pereira AV, Rotenberg L, Oliveira SS. Relações de gênero e interdependências: reflexões a partir de mudanças na configuração hospitalar. Hist cienc saudeManguinhos . 2013; 20: 1007-24.

14.Prata JA, Progianti JM. A influência da prática das enfermeiras obstétricas na construção de uma nova demanda social. Rev enferm UERJ. 2013; 21: 23-8. 